\title{
TORNANDO-SE PROFESSOR: ANÁLISE DO PROCESSO DE CONSTRUÇAO DA IDENTIDADE DOCENTE DOS PROFESSORES DE CONTABILIDADE
}

João Paulo Resende de Lima' Adriana Maria Procópio de Araujo²

Resumo: As discussões acerca da formação e atuação docente no ensino superior têm adotado um caráter tecnicista e impessoal tratando o docente como um mero objeto de estudo, deixando de lado dinâmicas sociais como o processo de construção de sua identidade profissional. Dessa maneira, o presente estudo tem o objetivo de compreender o processo de construção da identidade docente de professores de ciências contábeis. Foi adotada a abordagem qualitativa de pesquisa com evidências construídas por meio de entrevistas semiestruturadas com seis docentes na fase de "Estabilização" da carreira docente (quatro a seis anos) e analisadas a partir da construção de narrativas e análise temática que, alinhado com a literatura, originaram duas dimensões da identidade docente dos participantes da pesquisa: Trajetória e Docência. Acerca da dimensão "Trajetória" observou-se que os professores acumulam experiências profissionais e acadêmicas e guardam referências de professores que marcaram sua trajetória. Na análise da dimensão "Docência" foi observado que os professores experimentam situações e sentimentos negativos durante o começo da carreira, mas que vão se adaptando e aprendendo a lidar com situações diversas, construindo seus saberes experienciais. Os resultados também demonstram a necessidade de (re)pensar a inserção profissional de novos docentes, a formação acrítica e tecnicista desses, além de refletir sobre o papel que o docente tem perante as novas gerações e seus novos desafios.

Palavras-chave: Identidade Docente. Formação Docente. Ensino Superior. Contabilidade. 


\title{
BECOMING AN ACADEMIC: AN ANALYSIS OF ACCOUNTING TEACHER IDENTITY CONSTRUCTION
}

\begin{abstract}
Discussions about faculties training in higher education have adopted a technical and impersonal character treating faculties as a mere object of study, leaving aside social dynamics as the process of construction their professional identities. Thus, this study aims to understand the process of teacher identity construction of accounting faculties. We've adopted the qualitative approach of research and built evidence by conducting semi-structured interviews with six teachers in the "Stabilization" phase of the teaching career (four to six years). We analyzed such evidences through narrative and thematic analysis which, aligned with the literature, originated two dimensions of the teaching identity: Trajectory and Teaching. Regarding the dimesion "Trajectory", we observed that the participants accumulate professional and academic experiences and keep references of former faculties who were meaningful to their trajectory. In the analysis of "Teaching" dimesion we observed that teachers experience negative situations and feelings during the beginning of their career, but they adapt and learn to deal with different situations, building their experiential knowledge. The results also demonstrate the need to (re) think about the professional insertion of new teachers, their uncritical and technical training, as well as reflecting on the role that teachers have in the face of new generations and their new challenges.
\end{abstract}

Palavras-chave: Teacher identity. Teaching training. Higher Education. Accounting Education. 


\section{INTRODUÇÃO}

A s discussões acerca da formação docente, especialmente no âmbito do ensino superior, têm ganhado cada vez mais importância e destaque nas últimas décadas nos mais diversos centros de pesquisa e programas de pós-graduação (Slomski, Lames, Megliorini \& Lames, 2013; Carvalho \& Shigunov Neto, 2018). Contudo, os estudos desta linha têm ocorrido de maneira fragmentada, debruçando-se demasiadamente nas competências docentes e negligenciado outros aspectos relacionados à docência (Timostsuk \& Ugaste, 2010). Esta ênfase dada ao estudo das competências pode resultar na fragmentação do entendimento a respeito da formação docente, de sua imagem e campo de atuação, além de dificultar o entendimento dos diferentes aspectos da ação docente, reduzindo o docente a um check-list de competências e saberes necessários à docência.

Visando alterar tal cenário, desde a década de 1980, algumas pesquisas começaram a trazer o docente para seu centro na tentativa de (re)personifica-lo, abrindo caminho para as pesquisas acerca de sua Identidade Profissional, também conhecida como Identidade Docente (Diniz-Pereira, 2014). A Identidade Docente, apesar de ser um tema de pesquisa relativamente novo, cujo conceito permeia diferentes áreas (Guimarães, 2004, Beijaard; Meijer \& Verloop, 2004; Van Lankveld et al., 2017) é entendida como aspecto essencial da prática docente, pois "aponta a responsabilidade do professor para a sua função social, emergindo daí a autonomia e comprometimento com aquilo que faz" (Iza et al., 2014, p.276).

As pesquisas a respeito da Identidade Docente dos professores do ensino superior têm ganhado destaque a partir do final do século XIX e início do século XX devido ao acúmulo de tarefas relacionadas à docência e a pesquisa, que é hoje uma das principais características da docência nesse nível de ensino (Kreber, 2010; Fanghanel, 2012). Outro aspecto característico dos professores de ensino superior é sua formação, visto que, para este nível, os docentes costumam ser especialistas em suas respectivas áreas e não possuem forte formação pedagógica (Korkohenm \& Törmä, 2016).

Esta formação fragilizada no que se refere aos aspectos didáticos e pedagógicos não é diferente do cenário brasileiro, em que autores afirmam que existe apenas uma semi-formação para a docência (Maranhão \& Paula, 2009). Entretanto, tal cenário tem mudado e os docentes têm se conscientizado de que a docência em nível superior exige que o docente seja competente em sua área específica do conhecimento e tenha domínio na área pedagógica (Masetto, 2012), visto que o sucesso do ensino principal atividade do professor -, exige domínio e articulação de vários elementos (Slomski et al., 2013).

Acerca do processo de construção dessa identidade profissional são encontradas diversas teorias sociológicas e psicológicas que explicam tal processo. Para o presente estudo será adotada a vertente sociológica com na Teoria da Socialização Profissional (TSP) que preconiza que o processo de construção de identidades profissionais pauta-se pela não só pelo processo de formação convencional, mas também pela imersão no ambiente profissional e aprendizado da cultura de determinada profissão (Hughes, 1955; Erikson, 1968; Dubar, 2005).

Especificamente nos cursos de ciências contábeis, encontra-se quadro semelhante ao apontado acima. Trabalhos como o de Andere e Araújo (2008), Slomski et al. (2013) e Farias e Araujo (2016) apontam fragilidades na formação pedagógica dos docentes que atuam na área. Lima et al. (2015) afirmam que esta formação fragilizada acarreta um choque de realidade no início da carreira docente, pois "o sujeito 
dorme contador [...] e acorda professor". Esse início da carreira é um dos momentos cruciais, pois é é a fase em que os professores são principiantes buscando sua identidade profissional (Marcelo, 1998) e, em alguns casos, ainda sequer a possuem (Korkohenm \& Törmä, 2016).

Além da formação fragilizada, os estudos de identidade profissional se fazem necessário pois, historicamente, a literatura tem reduzido a professor a uma série de competências e saberes, impondo uma separação entre o "eu pessoal" e o "eu profissional", favorecendo o processo de desprofissionalização da docência e agravando a crise de identidade profissional docente (Nóvoa, 1992). Em relação à crise de identidade profissional na docência, Carrolo (1997) afirma que esse processo é derivado da descaracterização da docência devido a três fatores: (a) incompreensão e ausência de reconhecimento social da função docente; (b) indefinição institucional da escola a nível organizativo e pedagógico, a par da proliferação dos papéis exigidos ao professor; e (c) a deficiente percepção por parte dos professores do que é a sua profissão.

Com base no cenário apresentado o presente estudo visa compreender o processo de construção da identidade docente dos professores de ciências contábeis para responder à pergunta como ocorre o processo de construção da identidade docente dos professores dos cursos de ciências contábeis? O estudo justifica-se com base na necessidade de um maior entendimento a respeito da docência universitária e do processo de construção dos significados relacionados à docência pelos docentes que atuam nos cursos de contabilidade.

Especificamente na contabilidade, justifica-se para entender melhor a transição entre aluno e professor, já que atualmente essa transição é acompanhada de um choque de realidade causado pela formação fragilizada (Lima et al., 2015), além de ser uma lacuna teórica a ser preenchida, visto que na contabilidade a discussão sobre a formação dos professores assemelha-se ao cenário apresentado por Timostsuk e Ugaste (2010). O presente estudo contribui ao trazer uma nova perspectiva teórica para analisar a trajetória, formação e atuação docente em contabilidade, além de refletir sobre os processos de socialização de novos docentes da área e o sentido que esses docentes atribuem à docência.

\section{REFERENCIAL TEÓRICO}

\subsection{Identidade Docente: Entendendo seu conceito e construção}

Assim como a maioria das discussões centradas na educação, as pesquisas a respeito da identidade docente iniciaram-se com professores de ensino básico. Já as pesquisas envolvendo professores que atuam no ensino superior têm ganhado destaque a partir do final do século XIX, momento em que tais professores, além de lecionarem, começaram a ser cobrados para realizar pesquisas, negociando assim a identidade docente com a identidade de pesquisador (Kreber, 2010) e posteriormente começaram a se dividir também entre cargos de gestão universitária, avaliação e edição de artigos e periódicos, dentre outras atribuições (Remmik; Karm \& Lepp, 2013).

Apesar de o estudo da identidade pessoal ser um campo de pesquisa mais antigo, a identidade docente, especialmente a dos professores que atuam no ensino superior, é uma discussão recente (Saroyan \& Trigwell, 2015). Guimarães (2004) afirma que seu conceito é novo, complexo e com diferentes significados para diferentes ciências, assim a presente discussão visa trazer alguns delineamentos de tal identidade, mas não visa defini-la ou esgotar sua discussão.

Sugrue (1997) define essa identidade como parte de um discurso que está aberto à constante redefinição, já para Beijaard, Verloop e Vermunt (2000) tal identidade pode ser definida como a variação 
da percepção do professor a respeito de si mesmo como profissional. A partir de um levantamento de estudos acerca do tema Beijaard, Meijer e Verloop (2004) destacaram a ideia de que tal conceito não apresenta uma definição única, mas apresenta fatores em comum. Dentre tais fatores os autores destacam: a complexidade e construção contínua e a importância da reflexão "que professor eu quero ser?". Dessa forma, o processo de construção da identidade docente relaciona-se diretamente com a aprendizagem dos saberes e competências docentes.

Fanghanel (2012) afirma que a identidade docente representa as posições adotadas pelos professores em sua prática de acordo com suas crenças pedagógicas, emoções e entendimentos sobre o ensino, suas trajetórias e capacidades. No mesmo sentido, Pimenta e Anastasiou (2005) destacam que o significado social que os professores atribuem à educação e à profissão exerce grande importância durante o processo de construção da identidade docente, assim essa construção pode ser definida como um "processo de construção do sujeito historicamente situado" (p. 76).

Acerca do seu processo de construção, a literatura afirma que tal processo é complexo e envolve processos de construção, desconstrução e reconstrução (Pimenta \& Anastasiou, 2005; McNaughton \& Billot, 2016), que podem ser influenciados por diversos fatores contextuais - tais como o cenário sociocultural e o departamento no qual o docente atua, e organizacional, como a orientação da instituição em que atua,e as relações entre docência e gestão (Kreber, 2010); relações entre os pares, estudantes e si mesmo (Rodgers \& Scott, 2008); as percepções do indivíduo a respeito de si mesmo como professor, os objetivos educacionais e as concepções que o indivíduo tem a respeito dos aprendizes (Kreber, 2010); relacionados à formação docente inicial e continuada; profissionalidade docente; experiência e saber da experiência (Iza et al, 2014); fatores emocionais, cognitivos e morais relacionados à profissão (McNaughton \& Billot, 2016).

Ao assumir diversas funções o professor do ensino superior, consequentemente, acaba assumindo diferentes identidades simultaneamente (Fanghanel, 2012). Pimenta e Anastasiou (2005) afirmam, ainda, que a formação desempenha papel fundamental na construção da identidade profissional, pois este "inicia-se no processo de efetivar a formação na área" (op. cit. p. 105). Dessa forma, os anos passados na graduação funcionam como "preparação e iniciação ao processo identitário e de profissionalização dos profissionais de diferentes áreas" (op. cit. p. 105).

Considerando a pluralidade de fatores que compõem a identidade docente apresenta-se no Quadro 1 uma síntese de alguns estudos.

Quadro 1 - Fatores que influenciam a construção da Identidade Docente

\begin{tabular}{|c|c|c|}
\hline Autores & Objetivo & Resultados \\
\hline Chetty e Lubben (2010) & $\begin{array}{l}\text { Analisar o processo de construção da Identidade } \\
\text { Docente de professores da área de tecnologia. }\end{array}$ & $\begin{array}{l}\text { Os autores apontam que os entrevistados enxergam a } \\
\text { docência e a pesquisa como atividades dicotômicas e } \\
\text { realizam as pesquisas apenas para satisfazer as exigências } \\
\text { da universidade. Como formas de fortalecer a identidade } \\
\text { destes docentes os autores sugerem debates a respeito do } \\
\text { perfil esperado pela universidade e conversas entre os pares. }\end{array}$ \\
\hline Remmik, Karm e Lepp (2013) & $\begin{array}{l}\text { Entender a identidade docente de } 41 \text { professores } \\
\text { recém-formados e recém-contratados. }\end{array}$ & $\begin{array}{l}\text { Os resultados do trabalho indicam que os indivíduos } \\
\text { apresentam diferentes identidades, mas que podem ser } \\
\text { agrupados com base em fatores como formação, experiência } \\
\text { profissional anterior e das relações com os pares. }\end{array}$ \\
\hline $\begin{array}{l}\text { Pillen, Beijaard e Den Brok } \\
\text { (2013) }\end{array}$ & $\begin{array}{l}\text { Analisar o papel desempenhado pelos conflitos e } \\
\text { tensões no início da carreira. }\end{array}$ & $\begin{array}{l}\text { Os autores identificaram } 59 \text { tensões na prática e identidade } \\
\text { docente desses professores que poderiam ser categorizadas } \\
\text { em três grandes grupos: a mudança de aluno a professor; a } \\
\text { postura em relação aos alunos; e em relação às concepções } \\
\text { de ensino e a aprendizagem. Segundo os autores os principais } \\
\text { sentimentos que acompanham essas tensões são negativos, } \\
\text { relacionados à sensação de raiva, frustração e desamparo. }\end{array}$ \\
\hline
\end{tabular}




\begin{tabular}{|c|l|l|}
\hline Korkohenm e Törmä (2016) & $\begin{array}{c}\text { Identificar as diferentes maneiras que os docentes } \\
\text { vivenciam suas identidades profissionais. }\end{array}$ & $\begin{array}{l}\text { Na análise dos resultados foram encontrados dois construtos: } \\
\text { "construção de uma relação com o ensinar" - que trata o } \\
\text { modo que os professores estruturam sua prática docente } \\
\text { visando estabilizar sua identidade docente - e "a relação } \\
\text { com seu desenvolvimento como professor" - discute } \\
\text { o desenvolvimento profissional em um ambiente mais } \\
\text { sistemático. Os autores ainda desenvolveram uma tipologia } \\
\text { para classificar a identidade docente em três grupos: (i) } \\
\text { Development-oriented teacher identity; (ii) Constructive- } \\
\text { conflicting teacher identity e (iii) Unsolved teacher identity. }\end{array}$ \\
\hline McNaughton e Billot (2016) & $\begin{array}{l}\text { Explorar a mudança de papel e da identidade dos } \\
\text { professores universitários a partir da inserção de } \\
\text { vídeo-aulas na universidade em que estes atuavam. }\end{array}$ & $\begin{array}{l}\text { Os autores encontraram indícios que a inserção das vídeo- } \\
\text { aulas influenciou tanto a identidade quanto o papel destes } \\
\text { docentes, dado a mudança tecnológica causada no contexto. } \\
\text { Os autores ressaltam ainda a necessidade de os professores } \\
\text { estarem sem prontos para se adaptarem à novas realidades. }\end{array}$ \\
\hline \multicolumn{2}{|c|}{ Fonte: Lima e Ferraz (2018) }
\end{tabular}

Com base no Quadro 1 observa-se empiricamente a complexidade e riqueza de fatores que influenciam a (re)construção da identidade nas mais diversas áreas do saber.

\subsection{Caracterizando a Docência em contabilidade}

Acerca da atuação na docência em contabilidade são encontrados na literatura trabalhos que discutem os principais problemas enfrentados no exercício da docência, satisfação dos docentes com a profissão e discussões acerca do ciclo de vida profissional.

Conforme descrito por Lima et al. (2015) a falta da formação didático-pedagógica para o exercício da docência acaba caracterizando o início na docência pelo chamado "choque com a realidade". Acerca da atuação docente e necessidade de formação específica para a docência, Lima et al. (2015) afirmam que, devido ao cenário de mudanças rápidas e significativas que influenciam os processos de ensino e aprendizagem, é preciso refletir não apenas sobre a atuação e formação docente, suas múltiplas tarefas e exigências.

Araujo, Miranda e Pereira (2017) analisaram, a partir de um questionário, a satisfação dos docentes de contabilidade em relação à profissão docente e os sentimentos despertados e enfrentados ao decorrer da carreira. Os resultados demonstram que os respondentes estão satisfeitos com a profissão e afirmam gostar da profissão. Contudo, $44 \%$ afirmou que, às vezes, sente-se desanimado. Dessa forma, mesmo entre os profissionais satisfeitos com sua profissão existem momentos de desânimo.

Alguns trabalhos mesmo que não adotem o termo identidade docente abordam alguns de seus componentes. Ao adotar a concepção de identidade docente proposta por Fanghanel (2012) e os demais construtos que compõem a identidade - como a imagem e o estereótipo conforme afirma Brouard et al. (2017) - é possível encontrar trabalhos com aproximações da temática da identidade docente, como os trabalhos que analisam os sentimentos que permeiam a docência (Araujo, Miranda \& Pereira, 2017) e a imagem do professor perante aos alunos (Borges et al., 2014).

Outro trabalho que apesar de não utilizar o termo identidade docente se aproxima bastante da temática foi o trabalho desenvolvido por Ferreira (2015) que investigou a concepção do ser professor que fundamenta e dá sentido à prática de professores de uma universidade estadual brasileira, por meio de 12 entrevistas sobre suas trajetórias e atuação docente. Os resultados da pesquisa de Ferreira (2015) sugerem que os professores de contabilidade têm um senso de"ser-contador" bem mais forte do que "ser-professor". Dessa maneira, sentem-se contadores-professores e encaram o ensino como uma extensão de sua prática profissional.

Visando incentivar a construção da identidade docente nos professores de contabilidade Slomski e Martins (2008) sugerem a prática reflexiva como proposta metodológica. Os autores sugerem que para melhorar a formação e a profissionalização docente a formação deve possibilitar que os professores se tornem professores-investigadores que tenham competências "para investigar na, sobre e para a ação 
educativa e para partilhar resultados e processos com os outros, nomeadamente com os colegas"(p.10). Os autores afirmam que para formar professores-investigadores é preciso que as IES repensem a maneira que estão formando os professores de contabilidade.

\subsection{Teoria da Socialização Profissional e a construção de identidades}

A questão da identidade - de maneira geral, não só a profissional docente - tem sido foco de estudo de diferentes áreas e como resultado dessa pluralidade foram desenvolvidas diferentes teorias acerca das diferentes identidades (Faria \& Souza, 2011). Para a realização do presente trabalho é adotada a vertente sociológica com base na Teoria da Socialização Profissional (TSP) desenvolvida por Hughes (1955).

Tal teoria afirma que os processos de socialização da profissão permitem a construção da identidade profissional do indivíduo a partir da combinação da educação, do trabalho e da carreira (Hughes, 1955). Nesse sentido, Hughes (1955), ao estudar a construção da identidade de médicos, constatou que os estudantes não se tornavam médicos ao adquirir conhecimentos teóricos mas, sim, da imersão no trabalho real e de uma "conversão" em que os estudantes tinham contato com o mundo real da medicina, deixando para trás os estereótipos que tinham a respeito da profissão.

Hughes (1955) concluiu que a transição da identidade de universitário para médico acontecia mediante a soma da cultura da profissão, linguagem específica, da prática e da projeção profissional. Por fim, o autor ressalta a importância de estudos que considerem a vida profissional como um todo dando ênfase, principalmente, à formação inicial e aos primeiros anos de carreira, visto que são nestes momentos que a identificação com a profissão começa a tomar forma.

Ao considerarmos a vertente sociológica dos estudos de identidade consideramos que sua construção é resultado de "eventuais cisões como fruto de uma tensão ou contradição interna ao próprio mundo social" (Dubar, 2005, p. 137). Dubar (2005) afirma que cada indivíduo possui uma identidade para outro - que denomina que tipo de pessoa você é - e uma identidade para si - como você se enxerga/percebe. Apesar de as duas identidades passarem por processos distintos de construção ambas possuem um elemento em comum: a tipificação. Segundo Erikson (1968) as tipificações determinam que existe um número limitado de modelos socialmente significativos para a construção e combinação de identidades fragmentadas, sendo essas categorias úteis tanto para identificar os outros, quanto para se auto-identificar.

Tais identificações, apesar de úteis variam de acordo com o espaço social em que são exercidas e com a temporalidade biográfica (Dubar, 2005),assim, as identificações políticas, sociais ou do campo do trabalho não são as mesmas. Dubar (2005) afirma que não é possível definir a priori qualquer relação entre as diferentes categorias, contudo, defende a hipótese de que essas categorias dependem da fase da vida na qual o sujeito se encontra.

Outro ponto crucial para a TSP é o entendimento que ao ingressar em qualquer profissão o indivíduo já possui uma identidade profissional parcialmente desenvolvida, que após os processos de socialização se constitui em uma nova identidade profissional integrada à identidade pessoal (Cruess, Cruess, Boudreau, Snell \& Steinert, 2015). Dentre os elementos de socialização destacados na literatura encontram-se fatores pessoais e sociais (Gardner, 2008), as regras sociais e formais (Weidman, Twale \& Stein, 2001), além dos mentores e modelos (Cruess et al, 2015). 
A aplicação da TSP no campo das identidades docentes é encontrada nos trabalhos de: Lüdke e Boing (2004) que discutem a precarização do trabalho docente e seus impactos nos processos de socialização profissional; Alvez et al. (2007) que expõem de maneira teórica as contribuições de Dubar para os estudos de identidade docente; Fernandes (2016) que analisou a constituição identitária de professoras de enfermagem.

Na própria contabilidade a discussão acerca da socialização pode ser encontrada em trabalhos como Daoust e Malsch (2019) que discutem a socialização de ex-auditores e como tais profissionais recordam e constroem significados das experiências passadas na profissão; Fox (2018) que analisou a socialização de estudantes de doutorado em contabilidade; Farag e Elias (2016) que analisou a relação entre ceticismo, personalidade e nível de socialização dos estudantes de graduação de contabilidade.

\section{TRAJETÓRIA METODOLÓGICA}

Para alcançar o objetivo proposto foi adotada a abordagem qualitativa de pesquisa, que consiste em um conjunto de práticas interpretativas que transformam a realidade em uma série de representações, envolve uma abordagem naturalística e interpretativa do mundo. (Denzin \& Lincoln, 2005). Para este trabalho foi adotada a pesquisa narrativa como estratégia, que pode ser definida como o estudo da maneira que os indivíduos vivenciam o mundo (Conelly \& Clandinin, 1990).

A escolha da estratégia se deu com base na literatura que aponta que a identidade é afetada por fatores sociais e pelo contexto no qual o indivíduo está inserido. Kelchtermans e Ballet (2002) defendem o uso de pesquisas biográficas - como a narrativa - para o estudo dos professores, pois os colocam no centro do processo investigativo e dão significado às suas experiências e, principalmente, ao significado destas.

Para a construção de evidências foi adotada a entrevista semiestruturada com um guia de entrevistas construído a partir das indicações propostas por King (2004a), sendo que tal guia foi colocado à prova por meio da realização de três entrevistas-piloto. O recrutamento dos entrevistados, - tanto as entrevistas pilotos, quanto das entrevistas finais - utilizou como critério de inclusão o tempo de atuação como docente no ensino superior. O critério foi adotado com base no fato de que durante a fase de estabilização profissional os indivíduos "passam a ser professores, quer aos seus olhos, quer aos olhos dos outros" (Huberman, 2002, p.40).

Os resultados das três entrevistas-pilotos foram apresentados e discutidos com uma banca de especialistas a respeito do tema que fizeram sugestões de ajustes em relação à abordagem das entrevistas e das perguntas norteadoras das entrevistas. Em relação a abordagem da entrevista foi sugerido, e adotado, como método, a entrevista em profundidade com abordagem fenomenológica, conforme proposto por Seidman (2006) e adaptado por Soares Neto e Silva (2012).

Após os ajustes realizados pelo corpo de especialistas foram realizadas as entrevistas finais que serviram de base para as análises do presente trabalho. Tais entrevistas foram realizadas no período de outubro a dezembro de 2017 e totalizaram 12 entrevistas com sete participantes, conforme Quadro 1. Destaca-se que com um dos participantes não foi possível realizar a segunda rodada de entrevistas, dessa maneira, foram utilizadas entrevistas de apenas seis dos sete participantes.

Quadro 2 - Caracterização dos participantes das entrevistas finais

\begin{tabular}{|c|c|c|c|c|c|}
\hline Identificação & Tempo de Docência & Formação & Forma de entrevista & $\begin{array}{c}\text { Duração da Entrevista } \\
1\end{array}$ & $\begin{array}{c}\text { D u r a ç ã o } \\
\text { Entrevista 2 }\end{array}$ \\
\hline Augusto & 6 anos & Mestre & Skype/Skype & $58 \mathrm{~min}$ & $47 \mathrm{~min}$ \\
\hline
\end{tabular}




\begin{tabular}{|c|c|c|c|c|c|}
\hline Sophia & 6 anos & Mestra & Presencial/Presencial & $1 \mathrm{~h} 16 \mathrm{~min}$ & $1 \mathrm{~h} 13 \mathrm{~min}$ \\
\hline Vinicius & 5 anos & Mestre & Skype/Skype & $46 \mathrm{~min}$ & $37 \mathrm{~min}$ \\
\hline Clara & 5 anos & Mestra & Presencial/Skype & $43 \mathrm{~min}$ & $39 \mathrm{~min}$ \\
\hline Afonso & 6 anos & Doutor & Presencial/Skype & $46 \mathrm{~min}$ & $42 \mathrm{~min}$ \\
\hline Fernando & 5 anos & Doutor & Skype/Skype & $57 \mathrm{~min}$ & $50 \mathrm{~min}$ \\
\hline
\end{tabular}

Fonte: Elaboração própria Nota: todos os nomes apresentados são fictícios para proteger o anonimato dos/das participantes

Após a realização das entrevistas, essas foram transcritas e armazenadas em formato digital. Para a análise desses dados foi utilizada a abordagem Three-dimensional space (TDS), abordagem desenvolvida por Clandinin e Connelly (2000) com base na Teoria da Experiência de Dewey que conceitua a experiência como pessoal e social. Pode-se resumir a abordagem TDS em três elementos principais: (i) interação, (ii) continuidade e, (iii) situação/localidade.

Visando aprofundar a análise dos padrões encontrados nas narrativas foi realizda a análise categorial com o auxílio de templates com base nos pressupostos expostos por King (2004b). A análise tem como base a produção de uma lista de códigos (template) representando temas identificados na análise de dados textuais que, posteriormente, são agrupados de acordo com o tema central do grupo. $\mathrm{O}$ tema central do grupo de códigos é chamado de Higher Order Codes (traduzido aqui como Categorias), enquanto os códigos agrupados nesses temas são os Lower Order Codes (traduzidos nesse trabalho como Subcategorias).

Acerca da definição dos códigos, King (2004b) afirma que essa pode ser realizada a priori pelo pesquisador ou emergir a partir do texto, sendo que, nesse trabalho, os Higher Order Codes foram adotados a priori, seguindo a estrutura do guia de entrevista, enquanto os Lower Order Codes foram definidos conforme emergiram da análise. A partir dessa primeira categorização os dados foram categorizados uma segunda vez buscando temas em comum entre eles, sejam as opiniões sobre o tema divergentes ou semelhantes, construindo dessa maneira as Lower Order Codes.

\section{RESULTADOS E DISCUSSÕES}

\subsection{Trajetória Acadêmica \& Profissional}

A partir da análise das entrevistas transcritas foi possível chegar a oito categorias que se relacionam com a trajetória acadêmica e profissional dos participantes da pesquisa, sendo as categorias apresentadas no Quadro 3.

Quadro 3 - Template da análise da trajetória dos participantes

\begin{tabular}{|c|c|}
\hline Categoria & Subcategoria \\
\hline \multirow{4}{*}{ Trajetória Acadêmica e Profissional } & Pós-graduação stricto sensu \\
\cline { 2 - 2 } & Estágio docente \& monitoria \\
\cline { 2 - 2 } & Experiência como Aluno \\
\cline { 2 - 2 } & Experiências não docente \\
\cline { 2 - 2 } & Mestrado \\
\cline { 2 - 2 } & Professor Referência \\
\hline
\end{tabular}

Fonte: Elaboração própria com os dados da pesquisa

Segundo Lima, Vendramin e Casa Nova (2017), durante o curso de mestrado e doutorado, espera-se que os alunos construam tanto sua identidade como docente, quanto sua identidade como pesquisador. Guimarães (2004) e Pimenta e Anastasiou (2005) apontam para a importância do curso de mestrado 
e doutorado na construção da identidade docente, visto que é nesse momento que os profissionais com formação no bacharelado deveriam receber a formação pedagógica. Já na perspectiva da TSP o ingresso nos cursos de mestrado e doutorado pode ser visto como a imersão na profissão acadêmica, tal como mostram Gardner (2008) e Lima, Vendramin e Casa Nova (2017).

Então, porque do mestrado, porque da pós-graduação, foi titulação para me manter na área acadêmica e, aí, a minha ideia de mestrado era: "Eu vou aprender a ser professora no mestrado, porque o mercado não pede título de mestrado, mas se a docência está me pedindo para um concurso (Sophia).

E, aí assim, por isso que quando falei lá no mestrado, fiz uma crítica sobre nós não termos aprendido falar em público, a dar aula, especificamente [...] (Augusto).

[...] quando eu terminei o mestrado, abriu muitas portas na minha carreira, na minha vida. Porque seis meses depois, eu estava numa empresa de consultaria trabalhando com Riscos Internos. E eu estava na [IES] trabalhando no ensino a distância (Clara).

[quando eu] estava no mestrado... um rapaz enfartou depois de uma prova. E, da turma que entrou, acho, que treze, e saíram oito (Fernando).

[...] as aulas foram sofridas, essas foram. A minha lembrança de sofrimento vem daí, não vem da parte de pesquisa, não. Vem da parte de disciplina [...] Então, minha lembrança de sofrimento é essa. Eu aguentei por causa do meu orientador. Aguentei por causa dele, quem segurou a barra toda foi ele. Entendeu? (Vinicius).

A partir da análise dos trechos destacados é possível identificar três significados relacionados ao curso de mestrado: (i) o passo anterior à docência; (ii) aprimoramento profissional; e (iii) sofrimento e abdicação. O primeiro significado atribuído ao mestrado decorre da exigência que muitas instituições fazem em relação à titulação, visando atender as obrigações da legislação brasileira, que exige que uma parte de seu corpo docente tenha a titulação de mestre ou doutor.

Apesar de ser visto por alguns como o primeiro passo para a carreira docente, outros criticam o formato em que o curso de mestrado é oferecido, pois não dá subsídios para a formação de professores, como relata Augusto. Esse cenário já foi retratado em outros trabalhos como o de Farias e Araujo (2016) que indica que, na percepção dos docentes de contabilidade, a pós-graduação pouco contribui para a sua formação e prática docente. Esse resultado corrobora também com a contradição apontada por Laffin e Gomes (2016) que identificam que os programas declaram em seu objetivo a formação docente, no entanto, não a fazem de maneira orgânica, propiciando, no máximo, uma preparação. Apesar de a docência ser um dos campos que mais absorve os pós-graduandos, o mestrado também é visto como uma possibilidade de aprimoramento profissional para outras áreas, como demonstra o trabalho de Cunha, Cornachione Júnior e Martins (2010).

O terceiro significado, sofrimento e abdicação, é um tema que tem ganhado cada vez mais relevância no contexto acadêmico, pois cada vez mais são vinculadas notícias sobre quadros depressivos, suicídios e outros transtornos psíquicos. Trabalhos como o de Lima, Vendramin e Casa Nova (2017) e Altoé, Fragalli e Espejo (2014) relatam esse mesmo cenário de sofrimento e esgotamento físico e mental dos pós-graduandos em cenário nacional. O trabalho de Rezende et al. (2017) demonstrou que a média de estresse dos alunos de pós-graduação em contabilidade pode ser considerado alto e influencia, diretamente, seu rendimento acadêmico. Essa cultura de exigir cada vez mais dos estudantes em cursos de pós-graduação tem passado a se tornar uma regra social - não falada -, assim, tem sido incluído em modelos teóricos baseados na TSP, tal qual o modelo desenvolvido por Weidman, Twale e Stein (2001).

Ainda na trajetória, alguns dos participantes relataram a experiência de participar do estágio docente e, em um dos casos, realizar monitoria como aluno de graduação ainda. O estágio docente é visto, na literatura, como uma prática formativa muito positiva, pois aproxima o aluno da realidade da sala de aula, como aponta Andere e Araujo (2008) e Nganga et al. (2015). Pimenta e Lima (2004) destacam ainda 
o papel do estágio na construção da identidade docente, pois segundo as autoras o estágio é o local propício para a reflexão, construção e fortalecimento da identidade profissional docente.

Eu sempre tive um ótimo relacionamento com todos os professores que eu fiz o PAE. Mas muda muito; tem professor que te deixa mais solto, tem professor que te dá mais atividade, sei lá, administrativa para fazer. Outros professores que te inserem dentro da própria aula, algumas atividades nesse sentido (Vinicius).

Foi vendo o exemplo dele na prática e ele trocando uma ou outra experiência comigo né (Sophia). Primeiro, o meu primeiro estágio foi com o meu orientador mesmo. E eu escolhi a disciplina de acordo com o que eu gosto mesmo[...]. Depois, no doutorado, eu já estava preocupada com aprimoramento da didática. Então, eu escolhi o professor [NOME], que é um professor que é muito reconhecido no curso [CURSO] como uma pessoa que tem muita didática (Clara).

Com base nos depoimentos acima percebe-se que o interesse de cursar o estágio docente partiu dos alunos decorrente de dois motivos: aprimoramento didático e aprimoramento acerca de conteúdo. Outro ponto a ser destacado acerca da prática do estágio é a subjetividade do processo que, como afirmou Vinicius, varia muito de acordo com o professor. Apesar da importância da prática, Joaquim, Boas e Carrieri (2013) destacam a importância da preparação prévia para o estágio pois, sem o embasamento teórico, o estágio cai na prática da tentativa e erro, além de reforçar o valor da prática em detrimento da reflexão embasada na teoria.

Destaca-se ainda a influência clara de alguns docentes considerados modelos que motivaram a busca pelo estágio docente. Tais profissionais considerados modelos podem ser vistos como espelhos pelos novos entrantes na profissão e os auxiliam na reflexão "que professor eu (não) quero me tornar?" proposta por Beijaard, Meijer e Verloop (2004), além de constituírem um importante elemento da TSP como destaca Hughes (1955) e Cruess et al. (2015). Tal discussão de professores referências encontra ressonância em toda a trajetória acadêmica do indivíduo, pois como afirma Cunha (2009), ao decorrer da nossa experiência como aluno temos diversos professores que podem ser tomados como referências. Na análise da experiência como aluno, foram encontrados três perfis: o professor que era o aluno medíocre, o aluno médio e o bom aluno. Além disso, os professores relatam que, durante sua experiência de graduação, realizaram atividades como intercâmbio, iniciação científica e estágio, que contribuíram para a sua prática docente.

$\mathrm{Na}$ análise do professor referência foi possível identificar algumas características acerca dos professores que marcaram a trajetória dos participantes de maneira positiva e negativa.

[...] ela não me traz nenhuma lembrança boa, na verdade. Ela era muito rígida, acho que até extremo. (Augusto).

São caras que eram bons professores, que tinham um pacote de conhecimento interessante, tinham uma forma de transmitir esse conhecimento, interessante. (Afonso).

que essa é uma meta pra mim, de conseguir fazer com que as pessoas entendam que o nível tem que ser alto, mas a qualidade do ambiente não precisa [...] gerar competição, sabe?! (Fernando). [PROFESSOR] que é um professor que é muito reconhecido no curso de [CURSO] como uma pessoa que tem muita didática. (Clara).

Percebe-se, assim, que o professor referência dos participantes deve ser exigente, mas saiba equilibrar a exigência com o lado humano para que não gere desconforto para a sala e nem crie um ambiente de competição. São professores que possuem uma capacidade didática exemplar e que demonstrem domínio do conteúdo. Essas características são encontradas também no professor referência para os alunos de graduação no estudo de Miranda, Casa Nova e Cornacchione Junior (2012).

Finalmente, na análise da categoria "Experiências não docente", observa-se que todos os participantes da pesquisa relatam alguma experiência profissional antes do ingresso na docência. Entretanto, nem 
todas são relacionadas a área de contabilidade. Já os participantes que relatam a experiência profissional na área de contabilidade destacam os benefícios dessa experiência em sala de aula.

Acho que enriquece demais a aula. E, assim, possibilita a dar a disciplina de maneira diferente, caso não tivesse essa experiência. Sem dúvida nenhuma, é importante ter essa experiência no mercado e também experiência acadêmica. (Vinicius).

Não tenho dúvida que isso enriquece a aula, mesmo porque, às vezes... acho que... tentar trazer alguns conceitos para realidade dos alunos, é algo que faz com que eles tenham mais atenção na aula em si. (Augusto).

Essa experiência profissional não docente é apontada por Masetto (2012) como um dos componentes importantes para a formação e prática docente universitária pois, além de desenvolver os saberes teóricos da área de formação, possibilita que o docente esteja sempre atualizado e possa trazer para a sala de aula a sua experiência, deixando o conhecimento mais palpável para os alunos. Ferreira (2015) destaca ainda que essa prática profissional não docente fundamenta a prática de docentes da contabilidade na maioria das vezes.

\subsection{Docência e suas significações}

A presente categoria de análise refere-se à docência, analisando as relações, crenças e percepções que fundamentam a prática docente dos e das participantes da pesquisa, sendo dividida em unidades de análise apresentadas no Quadro 5.

Quadro 4 - Análise por template do tema Docência

\begin{tabular}{|c|c|}
\hline Categoria & Subcategoria \\
\hline \multirow{14}{*}{ Docência } & Aprendendo a Ser professor \\
\hline & Conflito geracional \\
\hline & Relaçōes \\
\hline & Proletarização do Ensino \\
\hline & Papel docente \\
\hline & Prática docente \\
\hline & Ensino $x$ Pesquisa \\
\hline & Perfil aluno \\
\hline & EAD $x$ Presencial \\
\hline & Autoimagem \\
\hline & Imagem Percebida \\
\hline & Sentimentos \\
\hline & Crença \\
\hline & Ser professor \\
\hline
\end{tabular}

Fonte: Elaboração própria com base nos dados da pesquisa

Como discutido brevemente no template da trajetória dos participantes, a pós-graduação, na maioria das vezes, não dá subsídio para o desenvolvimento do aluno para que este possa tornar-se docente, assim questiona-se: Como se aprende a ser docente? Nessa primeira categoria, a resposta foi consenso entre os participantes: aprende-se a ensinar, ensinando.

E parte do aprendizado é na prática, você vai aprendendo à medida que você vai vivenciando aquilo. Engraçado, eu acho que é bem isso. (Clara). 
Percebe-se que pela afirmação de Clara, o principal saber que baseia sua prática docente, é o saber experiencial. Tardif (2012) afirma que, ao decorrer da prática, o docente vai aprendendo a lidar melhor com as situações em sala de aula, desenvolvendo técnicas de improvisação e macetes que possibilitem ensinar com êxito.

Outro ponto que parece fundamentar a prática dos docentes de contabilidade é o conflito entre gerações, tanto gerações mais novas, quanto gerações mais antigas. Esse conflito é descrito pelos professores mais novos pela dificuldade de ensinar alguém que tem mais experiência de mercado e de vida que ele. Ao mesmo tempo em que aparece no discurso de Afonso o conflito com uma geração mais nova que se mostra mais contestadora e com limites mais rígidos acerca de alguns temas - tais quais equidade de gênero, homofobia, racismo etc.

Eu acho que uma das coisas que me assustava bastante era dar aula pra pessoas mais velhas do que eu, sempre achei tinha essa questão da idade e tal, mas era uma coisa muito mais minha. (Augusto).

Por exemplo, hoje em dia em sala de aula, tem certas brincadeiras que o pessoal já não entende como brincadeiras, né? Questões raciais, questões de homossexualismo, questões feministas, né? Coisas que na minha geração era brincadeira, hoje o pessoal já não aceita dessa forma. Então, a gente precisa modular por uma questão de respeito, precisa exercitar o respeito. (Afonso).

A fala de Afonso traz claramente não só um conflito geracional, mas também vai contra o saber "Respeito à autonomia" de Freire (2000). Segundo Freire (2000) o professor não pode possuir preconceitos seja relacionado à etnia, sexualidade ou qualquer outro tipo. É preciso que os professores não só descontruam tais preconceitos, mas também ajudem os alunos a superá-los, para que possam se formar cidadãos e contribuir para uma sociedade mais justa e igualitária, exercendo assim, a dimensão política do trabalho docente.

Outro ponto levantado sobre a docência tanto pelos participantes, quanto pela literatura, é o papel determinante que as relações exercem na prática docente e na construção da identidade docente. Dentre as relações apontadas pelos participantes, podem-se dividir: a relação entre os pares e a relação com os alunos. Acerca da relação com os pares foram encontrados dois tipos de relação: a relação cooperativa e a relação competitiva.

[...] eu não sei como os outros se sentem lá, mas eu sinto isso, que eu não estou hierarquicamente abaixo de ninguém. Obviamente, você deve respeito aos mais velhos, aos que você sabe que são professores produtivos, que tem... já há um respeito normal, adicional, vamos dizer assim. Então, é obvio que isso... mas mesmo esses, eles não me veem assim com essa... eu não sinto essa hierarquia. Então, é sempre "você pode", "você acha", "você gostaria", não é nada, "você vai fazer", "você tem que fazer". (Fernando).

Chamo de curral de pavão [a relação entre professores]. Cara, assim, não é só uma relação... não é só... você tem competição por recursos escassos, você tem instabilidade no emprego, você tem um baixo nível de enforcement, entendeu? Por que que as pessoas vão fazer esforço para engolir sapo num cenário desse que eu acabei de pensar? O que tem é a boa vontade de alguns. (Afonso).

A fala de Fernando traz à tona relações cooperativas que auxiliam a construção da identidade docente como mostrado pelo trabalho de Oliveira e Cruz (2017). Enquanto, a fala de Afonso, evoca a competição entre docentes por recursos, agravada pela crise financeira enfrentada pelas instituições públicas de ensino e órgãos de fomento. A fala de Afonso ainda revela um aspecto negativo da docência, muito vivenciado em instituições públicas: quanto maior o título, maior o ego. Essa prática baseada no ego é altamente criticada na literatura por autores como Rosa (1999), Freire (2000) e Demo (2010), que afirmam que o professor deve ter humildade no tratamento não só com os pares, mas também 
com os alunos. Demo (2010) ainda apresenta o conceito de "Argumento da Autoridade" que é a prática de professores utilizar o argumento de "eu sou o professor, você é o aluno, logo eu falo e você escuta".

Acerca da crise financeira vivenciada pelos órgãos de fomento, Afonso afirma que "a gente vive tempos estranhos na universidade". A fala de Afonso justifica-se não só pela crise das instituições públicas, mas, também, pelo processo proletarização que a docência vem passando graças ao avanço exponencial de instituições privadas.

Na verdade, a faculdade que eu leciono mudou a forma do EAD, a [IES], mudou a forma de ensinar à distância, que eu achei absurda e comercial e que eles estão realmente vendendo diplomas. Essa é a ideia. E eu estou ali, atrapalhando o processo, você viu, né? (Clara).

[...] algumas vezes você tem algumas instituições querendo vender esse diploma e o professor, às vezes, fica atrapalhando no meio desse negócio, querendo dar nota, dar trabalho. Fica atrapalhando. (Augusto).

Tem gente escondendo titulo para conseguir dar aula na [IES], na [IES], porque se apresentar o título é mandado embora. (Afonso).

Tanto a fala de Clara quanto a de Augusto demonstram que, nessa visão capitalista do ensino, o diploma é tratado como uma commoditye a figura do professor passa de um profissional disposto a ensinar, a auxiliar os alunos a se desenvolverem, para alguém que está ali para atrapalhar uma operação comercial. Já a fala de Afonso, retrata uma prática que tem sido noticiada há algum tempo: a contratação de professores com titulações altas durante o período de avaliação externa do MEC e a demissão desses professores após a avaliação. São práticas como essa que dificultam o processo de profissionalização da docência e a mantém com um status de ofício, tratando a docência como um complemento de renda ou "bico" (Silva, 2008).

Esses diversos fatores institucionais influenciam o processo de construção da identidade docente, tanto de maneira positiva, quanto de maneira negativa, como apontam Rodgers e Scott (2008) e Lankveld et al. (2017). Essa mudança de paradigma no ensino influencia, também, o papel docente e discente nos processos de ensino e aprendizagem. Outro fator institucional encontrado na literatura e levantando pelos participantes é a multiplicidade de funções que o professor universitário tem nos dias de hoje.

Eu acho que a gente está vivendo o paradigma do pato, né? A gente é tudo e não é nada, né? O pato não nada, não voa e não faz nada de direito. (Afonso).

A fala de Afonso encontra respaldo no trabalho de Casa Nova, Lourenço e Azevedo, (2018) que retrata a dificuldade de balancear o ensino, a pesquisa, extensão e administração da universidade. A relação entre ensino e pesquisa é vista pela literatura como conflituosa na construção da identidade docente, além de ser encarada como um elemento de socialização, visto que segundo Hughes (1955) a partir do ingresso na profissão ocorre um processo de hierarquização de tarefas.

Aí essa questão do ensino e pesquisa, eu não vejo o ensino sem pesquisa. (Clara).

Mas não é bem assim, você pode dar a melhor aula do mundo, mas se você for prestar concurso e não tiver lá um Lattes simpático, você está fora. (Afonso).

Eu consigo ver que tem professores que se dá mais numa área do que na outra, se dão melhor... Eu acho que eu tenho um bom trânsito nas duas. Acho, também, que quanto mais você pesquisa, você mais desenvolve seu olhar crítico para as coisas, e isso ajuda você em qualquer área da sua vida. (Fernando).

Com base nos trechos acima encontramos três visões sobre a relação entre o ensino e a pesquisa. A visão apontada por Clara traz a integração entre o ensino e pesquisa, que é o ideal, como aponta Demo (2010). Já a fala de Afonso tem como respaldo a prática do "publique ou pereça" (Broad, 1981). Por fim, a fala de Fernando remete a questão da afinidade com uma das atividades, que também 
encontra respaldo na fala de Demo (2010) que afirma que, apesar de não ser ideal, são encontrados esses perfis na academia.

Acerca dos alunos, são encontrados dois perfis na fala dos participantes. O primeiro perfil é o aluno mais jovem que não teve nenhum contato com o mercado de trabalho e está indo para o ensino superior aprender uma profissão, enquanto o outro, é o profissional que busca ascensão profissional por meio do estudo.

O problema dos que já estão mais velhos, é que eles já trabalham, eles têm muitas responsabilidades no trabalho. Em geral, têm família, né? E isso acaba tomando um pouco do tempo para estudo e, também, um pouco do tempo de aula, porque eles faltam mais. Já os mais novos, eles têm um pouco mais de pique, um pouco mais de gás. Então, dá para você acelerar algumas coisas e cobrar mais também extraclasse. (Fernando).

Essa mudança no perfil do aluno já foi retratada na literatura no trabalho de Lima et al. (2015). Assim, os docentes têm de estar preparados para lidar com a heterogeneidade em sala de aula, fazendo uso de técnicas e metodologias de ensino que possam envolver os dois perfis de alunos. Outra situação em que é encontrada uma heterogeneidade no perfil de alunos é na educação a distância (EaD).

\begin{abstract}
É bem mais cansativo que o presencial. Mas é uma experiência incrível. Eu acho que lecionei não só para uma região do país específica, lecionei para o país inteiro. Já teve um aluno que veio, me mandou um e-mail falando que não conseguiu fazer a minha prova, porque estava chovendo e ele não conseguiu pegar o barco para ir até o polo, imagina só, lá no Acre. A vitória é conseguir viver entre diferentes culturas, diferentes questões, né? E eu acho incrível, ensino a distância, justamente porque ele quebra as barreiras de distância, quebra a barreira... nos deixa mais próximos de várias regiões que talvez o ensino presencial não fosse possível de chegar com a qualidade que chega. (Clara).
\end{abstract}

A fala de Clara mostra que, quando bem utilizada, a expansão do ensino superior pode ser benéfica e mudar a vida de muitas pessoas que não teriam acesso à educação. Apesar das vantagens para os alunos, Clara ressalta que a modalidade EaD traz uma grande dificuldade para o professor: a falta de interação instantânea. Assim, o professor não consegue saber se está indo bem ao decorrer da aula ou não.

Especificamente, nas reflexões sobre a identidade docente, foram encontradas as seguintes unidades de análise: a autoimagem (identidade para si) e a imagem percebida (identidade para o outro) - conceitos teóricos da TSP como mostra Dubar (2005) - as crenças acerca do ensino, os sentimentos do ensino e a significação da profissão (ser professor). Na análise da identidade para si os professores se descrevem como exigentes, empáticos, justos e reconhecem seus vieses e a importância da formação.

Então, não me vejo como um uma professora apática, que entra na sala de aula e... e fica morta e fica desinteressada por aquilo que está... mesmo que eu não goste! Eu já dei uma disciplina de orçamento... Eu acho assim trabalhoso... aqueles exercícios enormes... às vezes, tem uma parte teórica que eu, às vezes, acho muito óbvia... mas, eu precisava mostrar para o aluno que ele precisa daquilo. (Clara).

[...] realmente, eu sou influenciado por ter vindo do mercado. Trabalhei em vários setores, no setor privado, no setor financeiro. Então, eu tenho uma forma de ver um mundo que não necessariamente é real. (Afonso).

Sou um professor exigente, em tudo, mas tenho empatia sobre os alunos, entendo as dificuldades. Eu gosto, por exemplo, de... nesse tema de dificuldade, só pra você entender, eu pego... dou exercícios pra casa e tal... e eu peço, num dia que eu não vou corrigir os exercícios ainda. Então, eu estou sempre pedindo exercícios adiante. Aí, eu olho todos, vejo onde eles estão errando, e se estou percebendo que eles não estão fazendo, eu paro, converso, tento entender qual que foi a questão em si... mas isso não faz com que eu seja menos exigente em relação ao estudo. (Fernando). 
Já na análise da imagem para os outros, principalmente para os alunos, os docentes acreditam ser vistos da mesma maneira que se descrevem e destacam iniciativas como mensagens enviadas pelos alunos e avaliações institucionais como respaldo para a descrição.

Acerca dos sentimentos que permeiam a docência são encontrados sentimentos negativos e positivos, estando os negativos mais ligados ao começo da carreira, o que pode ser explicado pelo choque de realidade retratado por Lima et al. (2015). Os sentimentos positivos que permeiam a docência podem explicar, pelo menos em parte, a satisfação que os docentes possuem acerca da profissão e são oriundos principalmente de situações de reconhecimento.

Fiquei nervoso, transpirei bastante. (Augusto).

É uma coisa interessante que na [nome da instituição] eu dei aula cinco anos, e agora eu vou receber meu quarto prêmio. Já tive uma vez que fui homenageado, uma vez patrono. E essa vai ser a segunda vez que eu vou ser nome de turma. (Fernando).

é um grande desafio a docência, mas cada:"Olha, professora, muito obrigada, eu não gostava de contabilidade, agora eu gosto" É... cada vez que escuto isso, é algo que não tem preço. (Clara).

Já na análise das crenças acerca do ensino, percebe-se que os participantes são bem tradicionais, mesmo tendo trabalhado e sido expostos a novas técnicas e metodologias de ensino, durante a profissão ou a formação.

eu ainda acho que educação funciona assim: quem sabe fala, quem não sabe senta e presta atenção. Eu sou bem tradicionalista com relação à educação. Tenho cá comigo minhas reservas com relação a certas metodologias. Acho que pode funcionar em certas áreas, certas disciplinas. (Afonso).

as pessoas em geral acreditam que o estudar é uma coisa chata, né? As pessoas não têm noção da força do ensino, do aprendizado. (Augusto).

Por fim, na análise são apresentados os trechos acerca do que significa ser docente para os participantes.

Maior ainda, né, é a minha vida. Eu vivo, vamos supor, 16 horas por dia, de segunda a segunda, é isso. São raros os... eu viajo muito pouco, eu saio muito pouco, eu trabalho muito. Estou na frente do computador muito constantemente. (Afonso).

Então, a educação me transformou assim. E, talvez, ser professor, é devolver um pouco disso. Mas, também, ter essa sensação de transformar as pessoas. (Fernando).

voltei para sala de aula e me apaixonei novamente. E, a cada disciplina que eu passo, cada semestre que termina, eu percebo que aquilo que eu quero seguir. Talvez em setembro, se estivesse a entrevista, eu falaria: "Olha, vou voltar para o mercado, não quero mais saber!" Mas, quando eu entro na sala de aula, a coisa muda, é diferente. $E$, eu percebo que você precisa se superar constantemente. Então, isso me fascina na sala de aula. (Clara).

Não desista! Mesmo, vale a pena, se você gosta do que você faz, tudo vale a pena. Mesmo que não tenha muito incentivo, mesmo que existam muitas adversidades, muitas questões para serem pensadas e questionados, vale a pena. Não desista. (Clara).

Observa-se, por meio significação da profissão para os participantes, o apreço e a paixão com que desenvolvem a docência, apesar de todas as dificuldades institucionais, de formação e de relacionamentos. Os participantes percebem a docência como um meio de modificar a sociedade para termos um mundo melhor. 
O curso de graduação em ciências contábeis é hoje um dos mais procurados e um dos que mais possui concluintes, conforme demonstram os dados do Censo do Ensino Superior de 2017. Isso tem levado à necessidade de novos docentes para lecionar nesses cursos. Entretanto, sem o oferecimento, a esses docentes, de uma formação específica para a atuação no ensino superior. Além do não oferecimento de formação específica, as contratações em massa - dentre outros fatores - contribuem para a desprofissionalização da docência e dificultam o entendimento completo do campo de atuação e da complexidade do ato de ensinar, reduzindo-o a mera transmissão de informações.

Dessa forma, a discussão acerca da formação e atuação, e mais recentemente sobre suas identidades profissionais, dos professores do ensino superior tem ganhado cada vez mais espaço, nos mais diversos centros de pesquisa. Especificamente sobre os professores que atuam em cursos de contabilidade, é comum que esses professores, ao decorrer de sua formação, construam sua identidade profissional como contadores e não como docentes. Assim, o presente estudo teve como objetivo compreender o processo de construção da identidade docente de professores que atuam em cursos de ciências contábeis e se encontrem na fase de estabilização profissional. Para alcançar o objetivo proposto foi adotada a abordagem qualitativa de pesquisa. Foram entrevistados dez docentes, alguns por mais de uma vez, entre entrevistas-piloto e entrevistas finais, cujas entrevistas foram transcritas e analisadas com base na abordagem TDS de análise de narrativas e aprofundadas com a técnica de análise temática com o uso de templates.

Dentre os resultados observou-se que o processo de construção da identidade docente dos professores de ciências contábeis ancora-se em duas principais categorias: Trajetória e Docência. Na categoria Trajetória foram analisados os aspectos que diz respeito às suas experiências como aluno ao decorrer de sua graduação, mestrado e doutorado e outras atividades profissionais não ligadas à docência. Por fim na categoria Docência são analisadas as experiências referentes à prática docente dos participantes, seus relacionamentos e sua imagem perante a si e perante os outros.

Vale destacar o fato dos participantes, ao contrário do apontado pela literatura, enxergarem a relação ensino x pesquisa como complementar e não como dicotômica. Por fim, percebe-se que os participantes se identificam com a profissão e, após superarem as dificuldades iniciais, experimentam sentimentos positivos que são reforçados pelo reconhecimento tanto dos pares, quanto dos alunos, dando significado à profissão e reforçando a sua identidade como docente.

As implicações para a prática são: para as instituições de ensino e seus gestores o estudo mostra a necessidade de formação continuada que pode ser propiciada por diversas maneiras como oficinas, workshops e palestras. Para os docentes em fase de formação, destaca-se a importância da conscientização acerca da necessidade de formação didático-pedagógica e do fato de que ela ocorrerá, na maioria das vezes, por conta própria. Para os docentes mais experientes e que atuam na formação de outros docentes, seja direta ou indiretamente, é preciso que incentivem os novos docentes a buscarem uma formação cada vez melhor, sirvam como mentores e exemplos positivos e, acima de tudo, reflitam sobre sua própria prática e incentivem os novos docentes a refletirem sobre a própria prática.

Para os órgãos de representação profissional que queiram ter um papel ativo na qualidade do profissional formado, atuando na qualificação docente, recomenda-se que instituam iniciativas que propiciem uma melhor formação docente e fóruns de discussão sobre a qualificação docente e seu impacto para a qualidade da formação profissional. Para profissionais contábeis que estejam considerando a docência, como atividade paralela ou principal, que reflitam sobre a importância da docência 
e do tempo que poderão se dedicar à docência, para que exerçam a docência de maneira responsável e não apenas como um "bico".

Como limitações da pesquisa, tem-se o perfil docente bastante restrito, visto que, em regiões mais afastadas do país, são poucos os professores que possuem titulação de mestre e doutor. Para pesquisas futuras, sugere-se o estudo aprofundado das emoções e crenças pedagógicas dos professores e como essas influenciam sua prática docente, as relações de gênero e raça na construção da identidade docente, o papel do estágio docente na construção da identidade docente e, por fim, a formação dos professores que formam novos professores.

\section{REFERÊNCIAS}

Alves, C. S., Cunha, D. D. O., Cunha, V. M., Gatti, B., Lima, L. F., Hobold, M., ... \& Rigolon, V. (2007). Identidade profissional de professores: um referencial para pesquisa. Educação \& Linguagem, 10(15), 269-283.

Altoé, S. M. L., Fragalli, A. C., \& Espejo, M. M. D. S. B. (2014). A "dor do crescimento": um estudo sobre o nível de estresse em pós-graduandos de contabilidade. Revista Gestão Universitária na América Latina-GUAL, 7(1), 213-233.

Andere, M. A., \& Araujo, A. M. P. (2008). Aspectos da formação do professor de ensino superior de ciências contábeis: uma análise dos programas de pós-graduação. Revista contabilidade \& Finanças-USP, 19(48), 91-102

Araújo, T. S., Miranda, G. J., \& Pereira, J. M. (2017). Satisfaction among accounting professors in Brazil. Revista contabilidade \& Finanças, 28(74), 264-281.

Beauchamp, C., \& Thomas, L. (2009). Understanding teacher identity: An overview of issues in the literature and implications for teacher education. Cambridge journal of education, 39(2), 175-189.

Beijaard, D., Meijer, P. C., \& Verloop, N. (2004). Reconsidering research on teachers' professional identity. Teaching and teacher education, 20(2), 107-128.

Beijaard, D., Verloop, N., \& Vermunt, J. D. (2000). Teachers' perceptions of professional identity: An exploratory study from a personal knowledge perspective. Teaching and teacher education, 16(7), 749-764.

Broad, W. J. (1981). The publishing game: getting more for less. Science, 211(4487), 1137-1139.

Carrolo, C. (1997) Formação e identidade profissional dos professores. In: Estrela, M. T. (Org.). Viver e construir a profissão docente. Porto: Porto Editora, (pp. 21-50).

Carvalho, R. A., \& Neto, A. S. (2018). Panorama da pesquisa sobre formação de professores no Brasil presente em periódicos da área de educação: análise da produção acadêmica entre os anos de $2000 \mathrm{e}$ 2016. Revista Brasileira de Iniciação Científica, 5(4), 106-118.

Casa Nova, S.P. C., Lourenço, I.C., \& Ferreira Azevedo, R. L. (2018). The misalignment between accounting faculty perceptions of success and organizational image during a process of institutional change. International Journal of Organizational Analysis, 26(5), 812-841.

Clandinin, D. J.; Conelly, F. M. (2000). Narrative inquiry: experience in story in qualitative research. 1. ed. San Francisco: Jossey-Bass.

Connelly, F. M., \& Clandinin, D. J. (1990). Stories of experience and narrative inquiry. Educational researcher, 19(5), 2-14. 
Cruess, R. L., Cruess, S. R., Boudreau, J. D., Snell, L., \& Steinert, Y. (2015). A schematic representation of the professional identity formation and socialization of medical students and residents: a guide for medical educators. Academic Medicine, 90(6), 718-725.

Cunha, M. I. (2009). Inovações pedagógicas: o desafio da reconfiguração de saberes na docência universitária. In: Pimenta, S. G.; Almeida, M. I. (Org.). Pedagogia Universitária. São Paulo: Editora da USP (pp. 211-235).

Cunha, J. V. A. D., Cornachione Junior, E. B., \& Martins, G. D. A. (2010). Doutores em ciências contábeis: análise sob a óptica da teoria do capital humano. Revista de Administração Contemporânea, 14(3), 532-557.

Cruess, R. L., Cruess, S. R., Boudreau, J. D., Snell, L., \& Steinert, Y. (2015). A schematic representation of the professional identity formation and socialization of medical students and residents: a guide for medical educators. Academic Medicine, 90(6), 718-725.

Daoust, L., \& Malsch, B. (2019). How ex-auditors remember their past: The transformation of audit experience into cultural memory. Accounting, Organizations and Society.Demo, P. (2010). Outra Universidade. 1. ed. Jundiaí: Paco Editorial.

Denzin, N. K.; Lincoln, Y. S. (2005). Introduction: the discipline and practice of qualitative research. In: .The sage handbook of qualitative research. 3. ed. Thousand Oaks: Sage Publications, (pp. 1-32).

Diniz-Pereira, J. E. (2014). Professores(as): identidades forjadas. In: Carvalho, C. H. C.; Castro, M. (Org.). Profissão docente: quais identidades?. 1ed.Uberlândia: EDUFU, 2014, v. 1, p. 55-71.

Dubar, C. (2005). A socialização: construção das identidades sociais e profissionais. 1. ed. São Paulo: Martins Fontes.

Fanghanel, J. (2012). Being an Academic. 1. ed. Londres: Routledge.

Farag, M. S., \& Elias, R. Z. (2016). The relationship between accounting students' personality, professional skepticism and anticipatory socialization. Accounting Education, 25(2), 124-138.

Faria, E., \& de Souza, V. L. T. (2011). Sobre o conceito de identidade: apropriações em estudos sobre formação de professores. Psicologia Escolar e Educacional, 15(1), 35-42.

Farias, R. S., \& Procópio de Araujo, A. M. (2016). Percepção dos professores de contabilidade quanto aos espaços formativos para o ofício da docência no Brasil. Revista de contabilidade e Organizações, 10(28).

Ferreira, M.M. (2015). Docência no ensino superior: aprendendo a ser professor de contabilidade. Tese de Doutorado, Universidade Federal de São Carlos.

Fernandes, C. N. S. (2016). Identidade profissional docente no ensino superior: caminhos de constituição na enfermagem. Tese de Doutorado, Escola de Enfermagem de Ribeirão Preto, Universidade de São Paulo, Ribeirão Preto. doi:10.11606/T.22.2017.tde-16012017-162323

Freire, P. (2000). Pedagogia da autonomia: saberes necessários à prática educativa. 15. ed. São Paulo: Paz e Terra.

Fox, K. A. (2018). The manufacture of the academic accountant. Critical Perspectives on Accounting, $57,1-20$.

Gardner, S.K. (2008).“What's too much and what's too little?": The process of becoming an independent researcher in doctoral education. The Journal of Higher Education, 79(3), 326-350. 
Guimarães, V. S. (2004). Formação de professores: saberes, identidade e profissão. 1. ed. Campinas: Papirus Editora.

Huberman, M. (2002). O ciclo de vida profissional dos professores. In: Nóvoa, A. (Org.). Vida de professores. Portugal: Porto Editora (pp. 78-101).

Hughes, E. (1955). The making of a physician-General statement of ideas and problems. Human organization, 14(4), 21-25.

Iza, D. F. V., Benites, L. C., Sanches Neto, L., Cyrino, M., Ananias, E. V., Arnosti, R. P., \& Souza Neto, S. D. (2014). Identidade docente: As várias faces da constituição do ser professor. Revista Eletrônica de Educação, 8(2), 273-292.

Joaquim, N. D. F., Vilas Boas, A. A., \& Carrieri, A. D. P. (2013). Estágio docente: formação profissional, preparação para o ensino ou docência em caráter precário?. Educação e Pesquisa, 39(2).

Kelchtermans, G., \& Ballet, K. (2002). The micropolitics of teacher induction. A narrative-biographical study on teacher socialisation. Teaching and teacher education, 18(1), 105-120.

King, N. (2004a). Using interviews in qualitative research. In: Cassel, C.; Symon, G. (Org.). Essential guide to qualitative methods in organizational research. Londres: SAGE Publications (pp. 11-22).

King, N. (2004b). Using templates in the thematic analyses of text. In: Cassel, C.; Symon, G. (Org.). Essential guide to qualitative methods in organizational research. Londres: SAGE Publications (pp. 256-270).

Korhonen, V., \& Törmä, S. (2016). Engagement with a teaching career-how a group of Finnish university teachers experience teacher identity and professional growth. Journal of Further and Higher Education, $40(1), 65-82$.

Kreber, C. (2010). Academics' teacher identities, authenticity and pedagogy. Studies in Higher Education, 35(2), 171-194.

Laffin, M.; Gomes, S. M. S. (2016). Formação pedagógica do professor de contabilidade: o Tema em Debate. Arquivos Analíticos de Políticas Educativas, 24 (77), pp. 1-31.

Lima, F. D. C., Oliveira, A. C. L. D., Araújo, T. S., \& Miranda, G. J. (2015). O choque com a realidade: dormi contador e acordei professor... REICE. Revista Electronica Iberoamericana sobre Calidad, Eficacia y Cambio en Educacion.

Lima, J. P. R. \& Ferraz, L. Z. T. (2018). “O que me torna professor?” Análise dos fatores constituintes da Identidade Docente em Contabilidade. In: Anais do XXI SemeAd.

Lüdke, M., \& Boing, L. A. (2004). Caminhos da profissão e da profissionalidade docentes. Educação \& Sociedade, 25(89).

Maranhão, C. M. S. A., \& Paula, A. P. P. (2009). Reflexões sobre a indústria cultural e o ensino em administração. Revista Brasileira de Docência, Ensino e Pesquisa em Administração, 1(2).

Marcelo, C. (1998). Pesquisa sobre a formação de professores: o conhecimento sobre aprender a ensinar. Revista Brasileira de Educação, 9, pp. 51-75.

Masetto, M. T. (2012). Competência pedagógica do professor universitário. 1. ed. São Paulo: Summus. $194 \mathrm{p}$.

McNaughton, S. M., \& Billot, J. (2016). Negotiating academic teacher identity shifts during higher education contextual change. Teaching in Higher Education, 21(6), 644-658. 
Miranda, G. J., Nova, S. P. D. C. C., \& Júnior, E. B. C. (2012). Os saberes dos professores-referência no ensino de contabilidade. Revista Contabilidade \& Finanças, 23(59), 142-153.

Nganga, C. S. N., Botinha, R. A., Miranda, G. J., \& Leal, E. A. (2016). Mestres e doutores em contabilidade no Brasil: uma análise dos componentes pedagógicos de sua formação inicial. REICE: Revista Electrónica Iberoamericana sobre Calidad, Eficacia y Cambio en Educación, 14(1), 83-99.

Nóvoa, A. A Formação de professores e profissão docente. (1992). In: Os professores e a sua formação. Lisboa: Publicações Don Quixote. pp. 13-33.

Oliveira, T. P., \& da Cruz, G. B. (2017). Inserção profissional docente no ensino superior. Education Policy Analysis Archives/Archivos Analíticos de Políticas Educativas, (25), 1-23.

Pimenta, S. G.; Anastasiou, L. G. C. (2005). Docência no ensino superior. 2. ed. São Paulo: Cortez. 279 p. Remmik, M., Karm, M., \& Lepp, L. (2013). Learning and Developing as a University Teacher: narratives of early career academics in Estonia. European Educational Research Journal, 12(3), 330-341.

Rezende, M. S.; Miranda, G. J.; Pereira, J. M.; Cornnachione Junior, E. B. (2017). Stress e Desempenho Acadêmico na Pós-Graduação Stricto Sensu em ciências contábeis no Brasil. Arquivos Analíticos de Políticas Educativas, 25(96), 1-23.

Rodgers, C. R.; Scott, K. H. (2008) The development of the personal self and professional identity in learning to teach. In: Cochran-Smith, M.; Feiman-Nemser, S.; Mcintyre, J. D. (Org.). Handbook of research on teacher education: enduring questions in changing contexts. Nova York: Routledge. p. 732-744.

Rosa, P. R. D. S. (1999). O que é ser Professor? Premissas para a definição de um Domínio da Matéria na área do Ensino de Ciências.

Saroyan, A., \& Trigwell, K. (2015). Higher education teachers' professional learning: Process and outcome. Studies in Educational Evaluation, 46, 92-101.

Seidman, I. (2006). Interviewing as qualitative research: A guide for researchers in education and the social sciences. Teachers college press.

Silva, P. P. (2008). A efetivação do princípio da indissociabilidade: um desafio para a Educação Superior. Ciência \& Desenvolvimento-Revista Eletrônica da FAINOR, 1(1), Pág-45.

Slomski, V. G., \& de Andrade Martins, G. (2008). O conceito de professor investigador: os saberes e as competências necessárias à docência reflexiva na área contábil. Revista Universo Contábil, 4(4), 6-21.

Slomski, V. G., de Lames, E. R., Megliorini, E., \& Lames, L. D. C. J. (2013). Saberes da docência que fundamentam a prática pedagógica do professor que ministra a disciplina de gestão de custos em um curso de ciências contábeis. Revista Universo Contábil, 9(4), 71-89.

Soares Neto, A., \& Barbosa da Silva, A. (2012). Os estágios de aprendizagem de auditores fiscais no contexto da prática profissional. Revista de Administração Pública-RAP, 46(3).

Sugrue, C. (1997). Student teachers' lay theories and teaching identities: Their implications for professional development. European Journal of Teacher Education, 20(3), 213-225.

Tardif, M. (2012). Saberes docentes e formação profissional. 13. ed. Petrópolis: Vozes.

Timoštšuk, I., \& Ugaste, A. (2010). Student teachers' professional identity. Teaching and teacher education, 26(8), 1563-1570.

Van Lankveld, T., Schoonenboom, J., Volman, M., Croiset, G., \& Beishuizen, J. (2017). Developing a teacher identity in the university context: A systematic review of the literature. Higher Education Research \& Development, 36(2), 325-342. 
Weidman, J.C., Twale, D.J., \& Stein, E.L. (2001). Socialization of Graduate and Professional Students in Higher Education: A Perilous Passage? ASHE-ERIC Higher Education Report, Volume 28, Number 3. Jossey-Bass Higher and Adult Education Series. Jossey-Bass, Publishers, Inc., 350 Sansome Street, San Francisco, CA94104-1342.

10 momento de discussão ocorreu durante a realização do exame de qualificação do mestrado do autor

2 "Suicídio de doutorado da USP levanta questões sobre saúde mental na pós", matéria veiculada no jornal Folha de São Paulo em 27 de outubro de 2017. Disponível em: <http://www1.folha.uol.com.br/ ciencia/2017/10/1930625-suicidio-de-doutorando-da-usp-levanta-questoes-sobre-saude-mental-na-pos.shtml?utm_source=facebook\&utm_medium=social\&utm_campaign=fbfolha $>$.

3 Estácio anuncia "demissão em massa" de professores, diz sindicato. Matéria veiculada no portal de notícias G1. Disponível em: < https://g1.globo.com/economia/noticia/estacio-promove-demissao-em-massa-de-professores-diz-sindicato.ghtml>.

\section{Como referenciar}

Lima, J. P. R. de; Araujo, A. M. P. de (2019). Tornando-se professor: análise do processo de construção da identidade docente dos professores de contabilidade. Advances in Scientific and Applied Accounting, 12(2), Maio / Ago. 